\title{
Mutation p.R I56H of KRTI0 responsible for severe phenotype of epidermolytic ichthyosis in a Chinese family
}

This article was published in the following Dove Press journal:

Therapeutics and Clinical Risk Management

I September 2014

Number of times this article has been viewed

\author{
Zhiliang Li',** \\ Qiao Liü,* \\ Aimin Wang ${ }^{2}$ \\ Hongsheng Wang' \\ Chengrang $\mathrm{Li}^{\prime}$ \\ 'Department of Dermatology, \\ Institute of Dermatology, Chinese \\ Academy of Medical Sciences and \\ Peking Union Medical College, \\ Nanjing, People's Republic of China; \\ ${ }^{2}$ Hainan Provincial Hospital of Skin \\ Disease, Hainan, People's Republic of \\ China \\ *These authors contributed equally to \\ this work
}

Correspondence: Chengrang Li Department of Dermatology, Institute of Dermatology, Chinese Academy of Medical Sciences and Peking Union Medical College, Jiangwangmiao Street, Nanjing, Jiangsu 210042, People's

Republic of China

Tel +86 I5298384673

Email nylcr72@।63.com

\section{Dear editor}

Epidermolytic ichthyosis is a rare genetic disorder characterized by diffuse erythroderma from the time of birth with subsequent appearance of thick, brown scales and occasional blister formation. Mutation has been found in keratin 1 (K1) and keratin 10 (K10) genes. ${ }^{1}$ Epidermolytic hyperkeratosis (EHK) is mostly inherited in a dominant mode. We report a Chinese family of EHK sufferers and their mutation findings.

The pedigree of the EHK family showed an autosomal dominant inheritance pattern (Figure 1). The proband, a 41 year-old Chinese woman, had erythroderma on the head, trunk, and extremities. She exhibited skin blistering, erosions, erythrodermic, and hyperkeratosis on the skin since infancy and the blistering and erosion gradually diminished with age. Physical examination revealed hyperkeratosis of the entire body (Figure 2A) and desquamation of the palm (Figure 2B). Her son, a 13 year-old boy, has a similar history and clinical manifestation. He was born with typical extensive erythroderma and bullae, and his skin was covered with hyperkeratotic patches of scales. Hyperkeratotic plaques can be seen on the back of the hand (Figure 2C), this lesion healed quickly after retinoid acid treatment (Figure 2D). Pathological examination of the upper portion of his left arm showed granular degeneration in the suprabasal layers (Figure 2E).

Direct sequencing of the whole coding regions of KRT1 and KRT10 was performed. A heterozygous KRT10 missense mutation c. $467 \mathrm{G}>\mathrm{A}$ (p.Arg156His) was identified in the proband and her son, while not in normal controls (Figure 2F and G). The mutation hotspots of EHK are located at the conserved sequences in helix initiative and helix terminal motifs of $\mathrm{K} 1$ and $\mathrm{K} 10 .^{2}$ The mutation of the reported family, c. $467 \mathrm{G}>\mathrm{A}$, just occurred at the hotspots. A previous study has revealed that the relationship between the genotype and phenotype in these patients was complex, not only dependent on the position of the mutation but also on the actual amino acid substitution. ${ }^{3,4}$ The p.R156 of KRT10 can be substituted by many amino acids such as serine, glycine, cysteine, histidine, and leucine, of which histidine is the most similar to arginine. Theoretically, the p.Arg156His mutation should be accompanied by a mild clinical manifestation, ${ }^{3}$ but the reported patients experienced severe conditions. So we cannot conclude that the more similar between two amino acid substitution in the same codon, the milder consequence will be brought. The p.Arg156His mutation is rather common in previous reports, ${ }^{2,4}$ but the clinical manifestations vary greatly. 


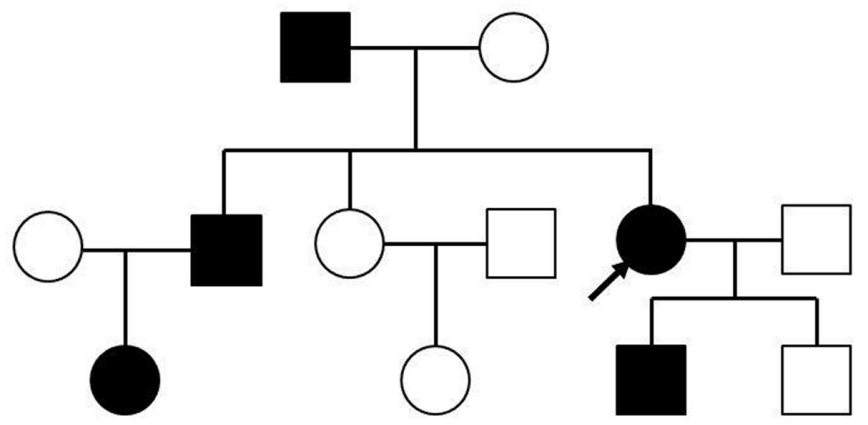

Figure I Pedigree figure.

Notes: Affected family members are represented by black symbols. Pedigree of the epidermolytic hyperkeratosis family studied. Arrow indicates the proband.
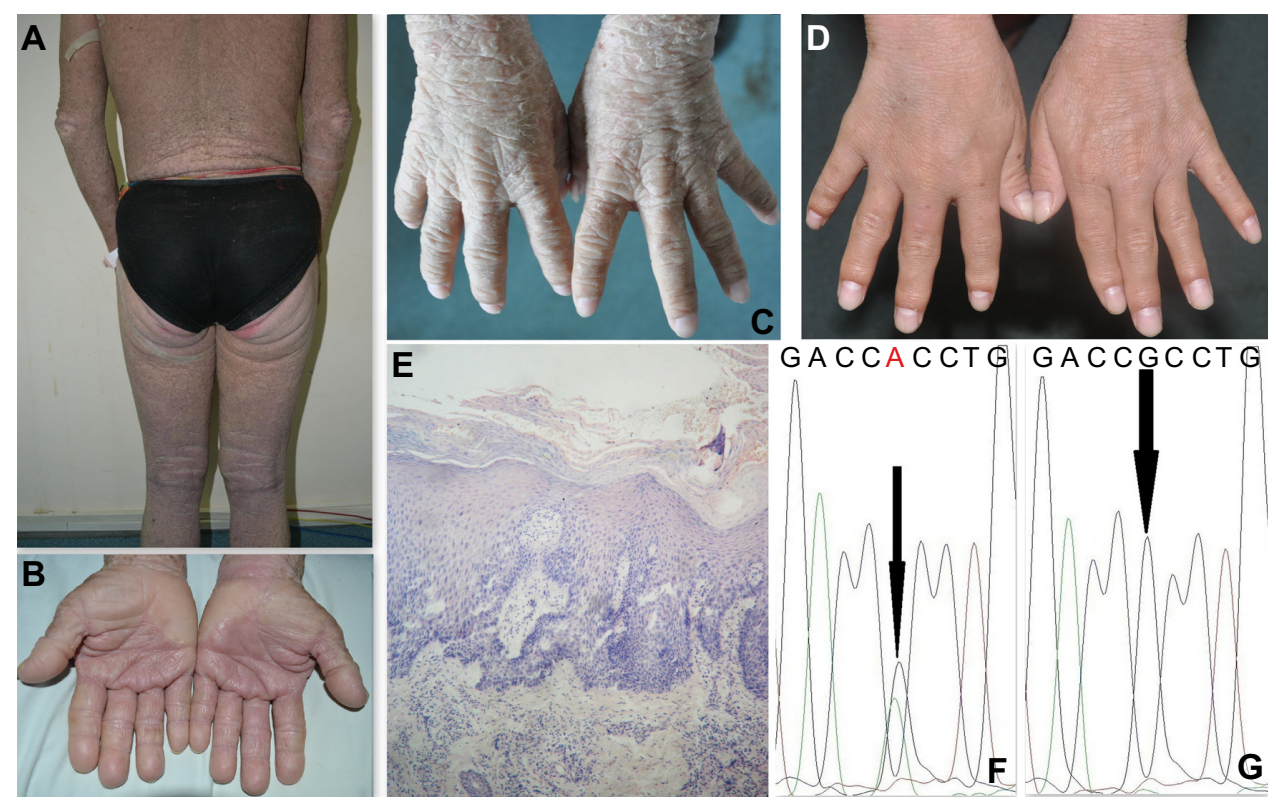

Figure 2 Clinical, histopathological, and gene sequencing of the patients.

Notes: Physical examination of the proband revealed hyperkeratosis and scales on the trunk and extremities (A) and desquamation of the palm (B). Hyperkeratotic plaques can be seen on the back of the hand of her son (C) and the lesion healed quickly after retinoid acid treatment (D). The histopathological examination of the proband revealed hyperkeratosis and acanthosis, severe granular degeneration in the spinous and granular layers of the epidermis (hematoxylin and eosin stain $\times 100)$ (E). Sequencing results of exon I of KRTIO from the patients (F) and from an unaffected individual (G). A heterozygous mutation c.467G $>$ A resulting in an arginine to histidine substitution in codon 156 (p.Arg I56His) of KRTIO was identified in the family.

Other genetic or epigenetic factors that were not identified may influence disease severity.

In conclusion, we confirm the diagnosis of epidermolytic ichthyosis in the two patients according to the genetic testing and this is beneficial for their genetic counseling. The results reveal that the mutation p.R156H of KRT10 is responsible for severe clinical manifestations in a Chinese family with EHK, and also confirm the complexity of the genotype-phenotype correlation in EHK.

\section{Acknowledgment}

We are indebted to the Foundation of PUMC innovation team, Teaching and Research Fund Project of PUMC (Grant No 2011zlgc0114, 303-05-8050).

\section{Disclosure}

No potential conflict of interest relevant to this work was reported.

\section{References}

1. DiGiovanna JJ, Bale SJ. Clinical heterogeneity in epidermolytic hyperkeratosis. Arch Dermatol. 1994;130(8):1026-1035.

2. Yang JM, Nam K, Kim SW, et al. Arginine in the beginning of the $1 \mathrm{~A}$ rod domain of the keratin 10 gene is the hot spot for the mutation in epidermolytic hyperkeratosis. J Dermatol Sci. 1999;19(2):126-133.

3. Sun XK, Ma LL, Xie YQ, Zhu XJ. Keratin 1 and keratin 10 mutations causing epidermolytic hyperkeratosis in Chinese patients. $J$ Dermatol Sci. 2002;29(3):195-200.

4. Arin MJ, Oji V, Emmert S, et al. Expanding the keratin mutation database: novel and recurrent mutations and genotype-phenotype correlations in 28 patients with epidermolytic ichthyosis. $\mathrm{Br} J$ Dermatol. 2011;164(2):442-447. 
Therapeutics and Clinical Risk Management

Dovepress

\section{Publish your work in this journal}

Therapeutics and Clinical Risk Management is an international, peerreviewed journal of clinical therapeutics and risk management, focusing on concise rapid reporting of clinical studies in all therapeutic areas outcomes, safety, and programs for the effective, safe, and sustained use of medicines. This journal is indexed on PubMed Central, CAS
EMBase, Scopus and the Elsevier Bibliographic databases. The manuscript management system is completely online and includes a very quick and fair peer-review system, which is all easy to use. Visit http://www.dovepress.com/testimonials.php to read real quotes from published authors.

Submit your manuscript here: http://www.dovepress.com/therapeutics-and-clinical-risk-management-journal 